\title{
Endothelin-1 in stable bronchiectasis
}

\author{
L. Zheng", G. Tipoe*, W-K. Lam ${ }^{\#}$, J.C.M. Ho", I. Shum ${ }^{\#}$, G.C. Ooi ${ }^{+}$, R. Leung ${ }^{\#}$, K.W.T. Tsang
}

Endothelin-1 in stable bronchiectasis. L. Zheng, G. Tipoe, W-K. Lam, J.C.M. Ho, I. Shum, G.C. Ooi, R. Leung, K.W.T. Tsang. (C)ERS Journals Ltd 2000.

ABSTRACT: Endothelin (ET)-1 has been suggested to promote neutrophil adhesion to endothelium, migration to inflamed areas, and release of elastase. ET-1 might therefore play a role in the pathogenesis of bronchiectasis, a chronic inflammatory and infective airway disease which is still poorly understood.

Thirty five patients with stable bronchiectasis ( 20 females, mean age \pm SD $49.1 \pm 15.0$ yrs) and 18 control subjects ( 8 females, $49.4 \pm 11.3$ yrs) were recruited prospectively. The ET-1 levels in serum and sputum were measured by commercially available enzyme linked immunosorbent assay (ELISA) kits.

Patients with Pseudomonas aeruginosa in their sputum had a significantly higher serum level of ET-1 (median 25.8, interquartile range $13-43.9 \mathrm{pg} \cdot \mathrm{mL}^{-1}$ ) than patients without $P$. aeruginosa $\left(0,0-10.5 \mathrm{pg} \cdot \mathrm{mL}^{-1} ; \mathrm{p}=0.0004\right)$ and healthy control subjects $(4.6$, $\left.0-16.3 \mathrm{pg} \cdot \mathrm{mL}^{-1} ; \mathrm{p}=0.002\right)$. However, patients with and without $P$. aeruginosa infection had no significant difference in sputum ET-1 level $(p=0.15)$. There was no correlation between serum or sputum ET-1 levels with the serum and sputum levels of the interleukin (IL)-1 $\beta$, IL-8 and tumour necrosis factor (TNF)- $\alpha$; the number of bronchiectasis lung lobes; and spirometry. Serum ET-1 level correlated with $24 \mathrm{~h}$ sputum volume for the bronchiectasis patients $(\mathrm{r}=0.51, \mathrm{p}=0.002)$.

The results, therefore, suggest a significant pathogenic role for endothelin-1 among Pseudomonas aeruginosa-infected patients with bronchiectasis. Further studies should be performed to evaluate the clinico-pathological correlation and expression of endothelin-1 in bronchiectasis.

Eur Respir J 2000; 16: 146-149.
University Depts of ${ }^{\#}$ Medicine, *Anatomy and ${ }^{+}$Diagnostic Radiology, The University of Hong Kong, Hong Kong SAR, China.

Correspondence: K.W.T. Tsang, University Dept of Medicine, Queen Mary Hospital, The University of Hong Kong, Pokfulam Road, Hong Kong SAR, China. Fax: 85228725828

Keywords: Bronchiectasis cytokines

endothelin-1

sputum

Received: September 301999

Accepted after revision March 82000

This study was supported by a CRCG grant of the University of Hong Kong.
Endothelin (ET)-1 is the most potent vasoconstrictor known [1] and has a wide range of biological activities in the respiratory tract [2-4]. Bronchiectasis is a chronic inflammatory and infective airway disease characterized by irreversible dilatation of the bronchi and, in many cases, by persistent production of purulent sputum. Neutrophils are the predominant cells found in the bronchiectatic airways. This neutrophil recruitment into the airways is partly mediated by airway pro-inflammatory cytokines including interleukin (IL)-1 $\beta$, IL-8 and tumour necrosis factor (TNF) $\alpha[5]$.

Human airway epithelial and endothelial cells and macrophages can all produce ET-1 [6-8], which promotes neutrophil adhesion to endothelial cells, migration to areas of inflammation and release of elastase in vitro [9-11]. The authors hypothesized that ET-1 might contribute to neutrophil trafficking into the airways, and play a significant role in the pathogenesis of bronchiectasis. The authors have, therefore, performed this study to investigate the levels of ET-1 in serum and sputum (sol), and correlated these with clinical and laboratory parameters in patients with steady state bronchiectasis.

\section{Methods}

\section{Subject recruitment}

Consecutive patients with proven bronchiectasis, diagnosed by high resolution computed tomography (HRCT), were recruited with written informed consent between March 1998 and February 1999. Inclusion criteria includ- ed: absence of asthma or other systemic diseases; no alteration in medication and dosage for at least 3 months; and "steady state" bronchiectasis as described previously [12]. Healthy control subjects, who were without respiratory, cardiovascular, gastrointestinal, renal and neurological diseases were recruited with verbal consent. Spirometry was measured with a SensorMedics 2200 (SensorMedics, Yorba Linda, CA, USA) package. Thoracic HRCT was performed within 12 months of the study, using a General Electric Hispeed Advantage Scanner (GE Medical Systems, Milwaukee, WI, USA). The number of lung lobes (including lingula) affected by bronchiectasis, as evident by the bronchial segment or subsegment being larger than the accompanying artery, was determined for each patient [13].

\section{Serum and sputum collection}

Fresh sputum was collected from bronchiectasis patients within $1 \mathrm{~h}$ of physiotherapy, and was used for all assessment. Sputum was ultracentrifuged $(100,000 \times \mathrm{g}$ for 30 min at $4^{\circ} \mathrm{C}$ ) to obtain the sol which, similar to serum, was stored at $-70^{\circ} \mathrm{C}$ until assay [12]. The volume of a $24 \mathrm{~h}$ sputum specimen was determined, to the nearest $0.5 \mathrm{~mL}$, as the mean of a three consecutive day collection [12].

Determination of serum and sputum endothelin-1, interleukin-8, interleukin-1 $\beta$, and tumour necrosis factor $\alpha$ levels

Undiluted serum and sputum sol levels of ET-1, IL-8, IL-1 $\beta$, and TNF $\alpha$ levels were measured, within the same 
day for each mediator, using commercially available enzyme linked immunosorbent assay kits (Biotra ELISA System; Amersham, Little Chalfont, Buckinghamshire, UK for ET-1; and R\&D Systems, Minneapolis, MN, USA). The sensitivity of the assay was $<24 \mathrm{pg} \cdot \mathrm{mL}^{-1}$ for ET- $1,<1$ $\mathrm{pg} \cdot \mathrm{mL}^{-1}$ for IL-1 $\beta, 2 \mathrm{pg} \cdot \mathrm{mL}^{-1}$ for IL-8 and $<5 \mathrm{pg} \cdot \mathrm{mL}^{-1}$ for TNF $\alpha$. The level of a mediator in a particular specimen was adopted as the mean of the duplicate specimens after referring to the standard curve. The coefficient variabilities of ET-1 level measurement, according to the manufacturer, were $3.5-6.6 \%$ within assay and $16.8-20.3 \%$ between assays.

Determination of sputum leukocyte density and elastase level

Sputum leukocyte density was determined by haemocytometry with the fresh sputum specimens serially diluted with phosphate buffered saline. Sputum sol elastase activity was determined as the mean of triplicate specimens. Briefly, a standard curve was constructed on the rate of change in optical density (at $410 \mathrm{~nm}$ ) after incubating known concentrations of elastase solutions (Sigma, Poole, Dorset, UK) with the chromogenic substrate succinyl-Lalanyl-L-alanine-p-nitroanilide (Sigma). By comparing with the standard curve, the rate of change in optical density determined at $410 \mathrm{~nm}$ was converted into elastase activity.

\section{Microbiological assessment of sputum}

Fresh sputum was obtained for microbiological evaluation [14]. Standard microbiological procedures were employed to identify all the sputum bacteria and classify them into pathogens (Pseudomonas aeruginosa and other species, Haemophilus influenzae, Moraxella catarrhalis, other Gram negative bacilli, Streptococcus pneumoniae, Staphylococcus aureus, and Mycobacteria) or commensal bacteria (Neisseria spp., $\alpha$-haemolytic streptococci, diptheroids, and coagulase-negative staphylococci) [12].

\section{Statistical analysis}

Comparisons between groups were made using the nonparametric Mann-Whitney rank order test. Correlations were evaluated by Spearman's rank method. A p-value $<0.05$ was taken as statistically significant.

\section{Results}

\section{Patient demographic data and clinical characteristics}

Patient demographic data and clinical characteristics are shown in table 1. There was no difference in age, forced expiratory volume in one second (FEV1) and forced vital capacity (FVC) between patients with and without $P$. aeruginosa infection $(\mathrm{p}>0.05)$. However, the number of bronchiectatic lung segments $(\mathrm{p}=0.03)$ and $24 \mathrm{~h}$ sputum volume $(\mathrm{p}=0.01)$ were higher among $P$. aeruginosa-infected patients compared with patients without $P$. aeruginosa.

Serum and sputum sol endothelin-1 levels, sputum leukocyte density, and sputum elastase levels

Patients with $P$. aeruginosa infection had a higher serum level of ET-1 compared with healthy control subjects $(\mathrm{p}=$ $0.002)$, and their counterparts ( $\mathrm{p}=0.0004$; fig. 1 ; table 1$)$.

Table 1. - Clinical characteristics, and levels of mediators in sputum and serum in subjects

\begin{tabular}{|c|c|c|c|c|}
\hline \multirow[t]{2}{*}{ Parameter } & \multirow[t]{2}{*}{ Control } & \multicolumn{3}{|c|}{ Bronchiectasis patients } \\
\hline & & All & PA-infected & Non-PA-infected \\
\hline $\mathrm{n}$ & 18 & 35 & 18 & 17 \\
\hline No. of females & 8 & 20 & 10 & 10 \\
\hline \multicolumn{5}{|l|}{ Clinical } \\
\hline Mean age \pm SD yrs & $49.4 \pm 11.3$ & $49.1 \pm 15.0$ & $48 \pm 16.0$ & $50 \pm 14.0$ \\
\hline Mean \pm SD FEV1 \% pred & - & $61.5 \pm 28.8$ & $53.4 \pm 27.9$ & $70.6 \pm 27.8$ \\
\hline Mean \pm SD FVC $\%$ pred & - & $75.2 \pm 25.9$ & $69.1 \pm 22.1$ & $81.9 \pm 28.9$ \\
\hline No. of bronchiectatic lung lobes & - & $3.4 \pm 1.3$ & $3.9 \pm 1.4^{*}$ & $2.9 \pm 1.1$ \\
\hline Median (range) $24 \mathrm{~h}$ sputum volume $\mathrm{mL}$ & - & $22(3-145)$ & $25(8-145)^{*}$ & $16(3-58)$ \\
\hline \multicolumn{5}{|l|}{ Sputum bacterial isolates } \\
\hline PA n & - & 18 & 18 & 0 \\
\hline Commensals $\mathrm{n}$ & - & 9 & 0 & 9 \\
\hline Haemophilus influenzae $\mathrm{n}$ & - & 4 & 0 & 4 \\
\hline Mycobacterium chalonae $\mathrm{n}$ & - & 1 & 0 & 1 \\
\hline Staphylococcus aureus $\mathrm{n}$ & - & 2 & 0 & 2 \\
\hline Streptococcus pneumoniae $\mathrm{n}$ & - & 1 & 0 & 1 \\
\hline \multicolumn{5}{|l|}{ Median (interquartile range) mediator levels } \\
\hline Serum ET-1 pg.mL $\mathrm{m}^{-1}$ & $4.6(0-16.3)$ & $11.8(0-30.6)$ & $25.8(13-43.9)^{*,+}$ & $0(0-10.5)$ \\
\hline Sputum ET-1 pg.mL $\mathrm{m}^{-1}$ & 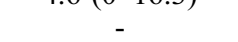 & $31.1(12.9-47.0)$ & $34.9(18.0-53.6)$ & $20.3(4.9-41.1)$ \\
\hline Serum IL-1 $\beta \mathrm{pg} \cdot \mathrm{mL}^{-1}$ & Undetectable & Undetectable & Undetectable & Undetectable \\
\hline Sputum IL-1 $\beta$ ng.mL $L^{-1}$ & - & $14.5(2.3-28.1)$ & $20.6(5.4-38.4)^{*}$ & $2.6(1.2-21.0)$ \\
\hline Serum IL-8 $\mathrm{pg} \cdot \mathrm{mL}^{-1}$ & $50.6(33.2-79.7)$ & $54.3(34.0-55.2)$ & $45.2(33.8-54.7)$ & $57.7(32.5-147.9)$ \\
\hline Sputum IL-8 $\mathrm{ng} \cdot \mathrm{mL}^{-1}$ & - & $19(6.8-44.8)$ & $23.4(12.0-47.3)$ & $8.9(4.3-40.7)$ \\
\hline Serum TNF $\alpha \mathrm{pg} \cdot \mathrm{mL}^{-1}$ & Undetectable & Undetectable & Undetectable & Undetectable \\
\hline Sputum TNF $\alpha \mathrm{pg} \cdot \mathrm{mL}^{-1}$ & - & $113.3(37.8-358.7)$ & $141.1(100-361)$ & $60.3(10-326)$ \\
\hline
\end{tabular}

No sputum was available from control subjects. ${ }^{*}$ and ${ }^{+}: \mathrm{p}<0.05$ when compared with patients who had no Pseudomonas aeruginosa (PA) infection and controls respectively. 
There was no difference in the sputum levels of ET-1 between $P$. aeruginosa and non- $P$. aeruginosa-infected bronchiectasis patients ( $\mathrm{p}=0.15$; fig. 2$)$. Sputum leukocyte density was higher in P. aeruginosa-infected (median 48.7, interquartile range $15.7-97.7 \times 10^{6} \cdot \mathrm{mL}^{-1}$ ) than in non- $P$. aeruginosa-infected patients $\left(9.1,1.5-25.5 \times 10^{6} \cdot \mathrm{mL}^{-1}\right.$; $\mathrm{p}=0.02$ ). Sputum sol elastase level was higher in $P$. aeruginosa-infected $\left(222.6,18.3-267.5\right.$ unit $\left.\cdot \mathrm{mL}^{-1}\right)$ than nonP. aeruginosa-infected patients $\left(8.7,0.6-186.7\right.$ unit $\cdot \mathrm{mL}^{-1}$; $\mathrm{p}=0.03)$.

Serum and sputum interleukin-8, interleukin-1 $\beta$ and tumour necrosis factor $\alpha$ levels

Table 1 depicts the IL- 8 , IL- $1 \beta$ and TNF $\alpha$ levels in serum and sputum of patients with and without $P$. aeruginosa-infection. Sputum IL-1 $\beta$ levels were higher among $P$. aeruginosa-infected patients compared with their counterparts $(\mathrm{p}=0.03)$. Sputum IL-8 and TNF $\alpha$ levels were not different between these two subgroups of bronchiectasis patients $(p>0.05)$. There was no difference in the serum levels of IL- 8 between the controls, and the patient groups $(p>0.05)$. Both serum IL-1 $\beta$ and TNF $\alpha$ levels were undetectable in patients with bronchiectasis and normal controls.

\section{Correlation analysis}

There was no correlation between serum or sputum ET-1 levels with the serum and sputum levels of the aforementioned pro-inflammatory mediators, number of lung lobes affected by bronchiectasis, FEV1 \% predicted, and FVC \% pred (data not shown; $\mathrm{p}>0.05$ ). However, serum, but not sputum, ET-1 levels correlated with $24 \mathrm{~h}$ sputum volume for the bronchiectasis patients $(\mathrm{r}=0.51, \mathrm{p}=0.002$, and $\mathrm{r}=$ $0.29, \mathrm{p}=0.87$, respectively). This correlation was only present in the subgroup of patients $(\mathrm{r}=0.43, \mathrm{p}=0.04)$ who had $P$. aeruginosa infection but not their counterparts $(\mathrm{r}=0.23$, $\mathrm{p}=0.19$ ). Amongst the bronchiectasis patients infected by $P$. aeruginosa, but not their counterparts, sputum IL-8 levels correlated significantly with sputum leukocyte density $(\mathrm{r}=0.57, \mathrm{p}=0.02)$. However, there was no correlation between sputum IL-8 with the other cytokine levels.

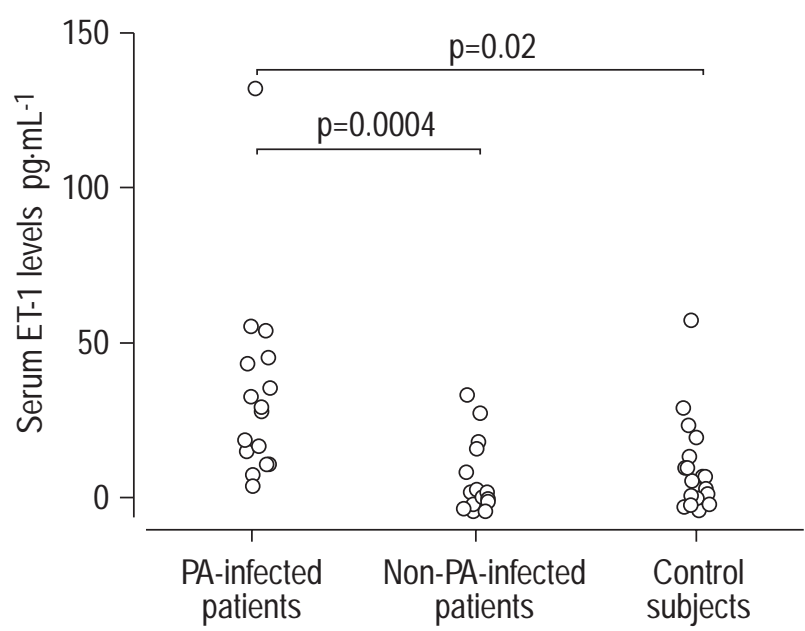

Fig. 1. - A scatterplot of serum endothelin (ET)-1 level in healthy control subjects $(\mathrm{n}=18)$ and patients with bronchiectasis (with $(\mathrm{n}=18)$ or without ( $\mathrm{n}=17)$ Pseudomonas aeruginosa (PA) infection).

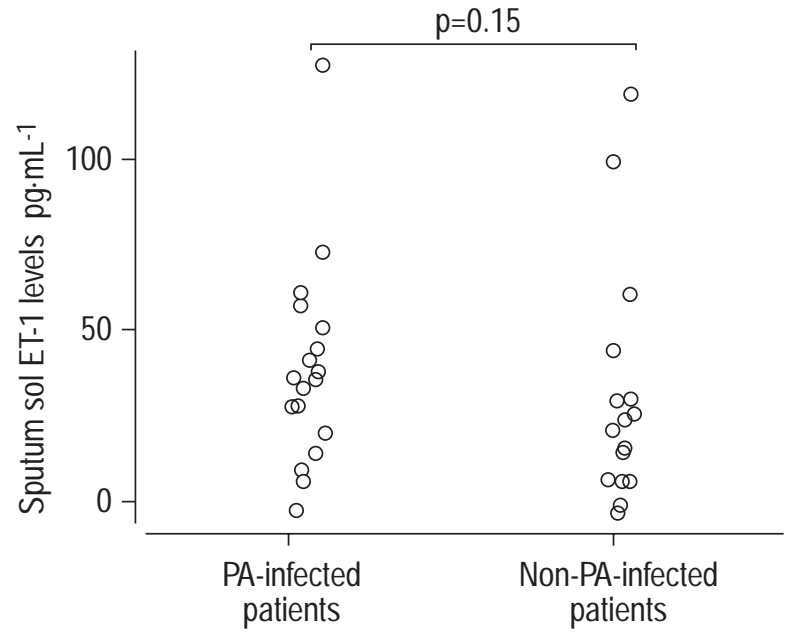

Fig. 2. - A scatterplot of sputum endothelin (ET)-1 level in bronchiectasis patients with $(\mathrm{n}=18)$ and without $(\mathrm{n}=17)$ Pseudomonas aeruginosa (PA) infection.

\section{Discussion}

The results of the study showed that serum level of ET1 , but not the other pro-inflammatory mediators evaluated (IL-8, IL-1 $\beta$ and TNF $\alpha$ ), was significantly raised among patients with $P$. aeruginosa infection compared with patients without $P$. aeruginosa infection and healthy controls. However, there were no significant differences between $P$. aeruginosa infected and non- $P$. aeruginosa-infected patients in their sputum levels of ET-1, IL-8 and TNF $\alpha$ (table 1). Serum, but not sputum, ET-1 levels correlated with 24 h sputum volume in the entire cohort of bronchiectasis patients although this correlation did not exist for non- $P$. aeruginosa-infected patients. Sputum levels of IL-1 $\beta$, elastase activity, leukocyte density, $24 \mathrm{~h}$ sputum volume and the number of lung lobes affected by bronchiectasis were significantly higher in $P$. aeruginosa-infected than in non-P. aeruginosa-infected patients [14]. Sputum IL-8 level correlated with sputum leukocyte density in $P$. aeruginosa-infected patients but not their counterparts. Interpretation of ET-1 sputum level was hindered by the lack of sputum data from control subjects. However, sputum ET-1 levels in the bronchiectasis patients (median 31.1, interquartile range $12.9-47.0 \mathrm{pg} \cdot \mathrm{mL}^{-1}$; table 1) appear to be lower than those reported in patients with cystic fibrosis $\left(77.6,29-122.8 \mathrm{pg} \cdot \mathrm{mL}^{-1}\right)$, but higher than in those with chronic obstructive pulmonary disease $(16.4,6.8-$ $\left.38.2 \mathrm{pg} \cdot \mathrm{mL}^{-1}\right)[15]$.

Although ET-1 has been implicated in the pathogenesis of asthma, fibrosing alveolitis and pulmonary hypertension [2-4], little is known of its role in bronchiectasis. The chemotactic and elastase-inducing properties of ET-1 might help to activate recruited neutrophils, and lead to further airway damage in bronchiectasis [9-11]. The higher serum but not sputum levels of ET-1 amongst bronchiectasis patients with $P$. aeruginosa infection suggests that ET-1 might predominantly act at peri-vascular rather than intra-bronchial sites. This is further supported by the correlation between serum, but not sputum, levels of ET-1 with 24 h sputum volume, which reflects "leukocyte trafficking" into the bronchiectasis airways. Alternatively, there might have been an increase in sputum 
level of ET-1 among $P$. aeruginosa-infected patients, but the ET-1 could have undergone degradation by activated neutrophils in vivo [16]. As P. aeruginosa-infection occurs frequently in patients who have severe bronchiectasis [14], the increased serum ET-1 detected in P. aeruginosainfected patients could merely reflect disease severity independent of $P$. aeruginosa infection. This is a less likely explanation as ET-1 levels did not correlate with the number of lung segments affected by bronchiectasis or spirometry. It is therefore likely that the high levels of ET-1 detected in $P$. aeruginosa-infected patients genuinely reflects an up-regulation of ET-1 expression by $P$. aeruginosa infection. Other bacterial products such as Escherichia coli lipolysaccharide and pro-inflammatory cytokines, such as IL-1 $\beta$ and TNF $\alpha$ also up-regulate ET-1 expression in human bronchial epithelium [6].

Migration of neutrophils from the intravascular compartment to an inflammed tissue requires interaction of neutrophils with vascular endothelium and the presence of chemoattractants which serve as homing triggers. ET-1 upregulates the expression of adhesive molecules, CD18 and CD11b on neutrophil surface, and enhances neutrophil adhesion to pulmonary endothelium $[9,11,17]$. The findings of an elevated serum ET-1 in P. aeruginosa-infected patients, but not the other pro-inflammatory cytokines, suggests an important role for ET-1 in the endothelial recruitment of neutrophils in bronchiectasis. Moreover, IL- 8 and IL- $1 \beta$ are highly potent neutrophil chemotactic factors [8] whose production by human airway epithelial cells is up regulated by $P$. aeruginosa products [18]. The results show that there was a correlation between sputum IL-8 levels and leukocyte density among the $P$. aeruginosa-infected patients. The data, therefore, suggest that the extensive airway recruitment of neutrophils in bronchiectasis patients infected by $P$. aeruginosa might be due to high levels of ET-1 in circulation, and IL- 8 and IL-1 $\beta$ peri-bronchially.

The authors' original data show that endothelin-1 expression was increased amongst patients with severe bronchiectasis who had Pseudomonas aeruginosa infection. This was also accompanied by simultaneous increase in sputum leukocyte density and sputum elastase activity in these patients. The results, therefore, suggest a significant pathogenic role for endothelin-1 in Pseudomonas aeruginosa-infected bronchiectasis. It is possible that peri-vascular endothelin-1, up-regulated by Pseudomonas aerugino$s a$ infection, could collaborate with the intra-bronchial actions of interleukin- $1 \beta$ and interleukin- 8 to initiate or maintain the heavy neutrophil trafficking, which is an essential step in the pathogenesis of bronchiectasis.

\section{References}

1. Yanagisawa M, Kurihara H, Kimura S, et al. A novel potent vasoconstrictor pepide produced by vascular endothelial cells. Nature 1988; 332: 411-415.

2. Mattoli S, Soloperto M, Marini M, Fasoli A. Levels of endothelin in the bronchoalveolar lavage fluid of patients with symptomatic asthma and reversible airflow obstruction. J Allergy Clin Immunol 1991; 88: 376-384.

3. Saleh D, Furukawa K, Tsao MS, et al. Elevated expression of endothelin-1 and endothelin-converting enzyme-1 in idiopathic pulmonary fibrosis: possible involvement of proinflammatory cytokines. Am J Respir Cell Mol Biol 1997; 16: 187-193.

4. Giaid A, Yanagisawa M, Langleben D, et al. Expression of endothelin in the lungs of patients with pulmonary hypertension. N Engl J Med 1993; 328: 1732-1739.

5. Schleimer RP, Benenati SV, Friedman B, Bochner BS. Do cytokines play a role in leukocyte recruitment and activation in the lung? Am Rev Respir Dis 1991; 143: 11691174.

6. Ehrenreich H, Anderson RW, Fox CH, et al. Endothelins, peptide with potent vasoactive properties, are produced by human macrophages. $J$ Exp Med 1990; 172: 17411748.

7. Nakano J, Takizawa H, Ohtoshi T, et al. Endotoxin and proinflammatory cytokines stimulate endothelin-1 expression and release by airway epithelial cells. Clin Exp Allergy 1994; 24: 330-336.

8. Giaid A, Polak JM, Gaitonde V, et al. Distribution of endothelin-like immunoreactivity and mRNA in the developing and adult human lung. Am J Respir Cell Mol Biol 1991; 4: 50-58.

9. Lopez-Farre A, Riesco A, Espinosa G, et al. Effect of endothelin-1 on neutrophil adhesion to endothelial cells and perfused heart. Circulation 1993; 88: 1166-1171.

10. Halim A, Kanayama N, El Maradny E, Maehara K, Terao T. Activated neutrophil by endothelin-1 caused tissue damage in human umbilical cord. Thromb Res 1995; 77: 321-327.

11. Eliferink JGR, de Koster BM. Endothelin-induced activation of neutrophil migration. Biochem Pharmacol 1994; 48: 865-871.

12. Tsang KW, Ho PL, Lam WK, et al. Inhaled fluticason reduces sputum inflammatory indices in severe bronchiectasis. Am J Respir Crit Care Med 1998; 158: 723-727.

13. McGuniness G, Naidich DP, Leitman BS, McCauley DI. Bronchiectasis: CT evaluation. Am J Radiol 1993; 160: 253-259.

14. Ho PL, Chan KN, Ip SM, et al. The effect of Pseudomonas aeruginosa infection on clinical parameters in steady-state bronchiectasis. Chest 1998; 114: 1594-1598.

15. Chalmers GW, Macloed KJ, Sriram S, et al. Sputum endothelin-1 is increased in cystic fibrosis and chronic obstructive pulmonary disease. Eur Respir J 1999; 13: 1288-1292.

16. Sessa WC, Kaw S, Zembowicz A, Anggard E, Hecker M, Vane JR. Human polymorphonuclear leukocytes generate and degrade endothelin-1 by two distinct neutral proteases. J Cardiovasc Pharmacol 1991; 17: s34-s38.

17. Helset E, Ytrehus K, Tveita T, Kjaeve J, Jorgensen L. Endothelin-1 causes accumulation of leukocytes in the pulmonary circulation. Circ Shock 1994; 44: 201-209.

18. Massion PP, Inoue H, Richman-Eisenstat J, et al. Novel Pseudomonas product stimulates interleukin-8 production in airway epithelial cells in vitro. J Clin Invest 1994; 93 : 26-32. 